\title{
The Major Cause of Lameness and Associated Risk Factors in Working Donkey in and around Hawassa Town, Ethiopia
}

Guluma Assefa ${ }^{1}$, Birhanu Abera ${ }^{2 *}$, Ahmed Nur ${ }^{1}$, Diriba Lemma ${ }^{2}$, Lamessa Keno ${ }^{1}$, Eyob Eticha ${ }^{2}$, Gebeyehu Chali ${ }^{3}$ and Mahammed Hussen

${ }^{1}$ East Shoa Zone Livestock and Fishery Resource Office, Adama, Ethopia

${ }^{2}$ Asella Regional Veterinary Laboratory, Asella, Ethiopia

3llu Aba Bor Zone Livestock and Fishery Resource Office, Mattu, Ethioipia

${ }^{4}$ Buno Bedelle Zone Livestock and Fishery Resource Office, Bedelle, Ethiopia

\begin{abstract}
Across sectional study survey of the major work related lameness in donkey in and around Hawassa was under taken to determine the main causes of lameness in working donkeys and associated risk factor s. A total of 205 lame donkeys have been examined and their owners were interviewed to assess the possible cause of lameness and the type of management conditions. The result reveal that donkeys found in study area mainly cart pulling donkeys $(96.5 \%)$ and about $99.5 \%$ of working donkeys are male. The result of questioner survey and visual study reveal that the main causes of lameness in donkey are $; 28.3 \%$ is muscular and tendon problem, $21.5 \%$ is joint problem, $5.4 \%$ is bone problem, $20.0 \%$ is tendon problems, $13.2 \%$ is hoof problem and $27.0 \%$ is other associated risk factor were shown to cause lameness in working donkey with the extreme significant $(p<0.0001)$.the major types of lameness encountered during the study was supportive leg lameness $(47.3 \%)$ and with the least of non weight bearing lameness were encountered with the significant of $(p<0.0001)$.the result of this study suggested that in spite of varies use of donkey; they are confronted by series of health and welfare problem. Joint problem, tendon problem, hoof problem, bone problem and other relative risk factor; abusing, over loading, over working and unnecessary neglect and general maltreatment that are causing lameness are still prevalent health and welfare problem. The public veterinary clinic is almost lacking medical equipment and medicine; meant foot treating of lame donkey, therefore, further study on lameness and welfare constraints hindering the efficient use of donkey in region is of paramount importance.
\end{abstract}

Keywords: Donkey; Lameness; Risk factors; Hawassa; Ethiopia

\section{Introduction}

The equine population of the world was reported to be 122.4 million with 40 million donkeys, 15 million mules and 43.3 million horses. In the distribution pattern, $98 \%$ of all donkeys, $97 \%$ of all mules and $60 \%$ of all horses were noted to be found in developing countries [1]. The number of equines in Africa was in the range of 17.6 million comprising 11.6 million donkeys, 2.3 mullion mules and 3.7 million horses. Ethiopia possessed approximately half of Africa's equines population with $37 \%$, $58 \%$ and $46 \%$ of all Africa, donkeys, horses and mules, respectively [2].

According to recent CSA (2014), there are about 2.03 million horses, 7.43 million donkeys, 0.4 million mules, and about 1.16 million camels in the sedentary areas of the country [3]. In Ethiopia the use of donkeys as pack animal or for pulling cart has enabled small scale farmers to participate in the market economy. Donkeys are used for fetching water, for household shifting, for carrying the sick to hospital, for carrying sick calves, for transportation, hoping and for pulling materials needed for construction [4]. Despite their remarkable contributions, donkeys in Ethiopia are the most neglected animals accorded low social status [5].

Although, equine play a significant role in the economy of the country, the government livestock development programs and those of aid agencies are aid toward increasing milk, meat, egg and wool production. Equines have been completely neglected and omitted from the agricultural system and their role in production is not yet well recognized and magnified. In country where there is less developed modern transportation and communication services. The natural choice rest on the use of human and pack animal mode of transport and it has been the case in the some part of the world. This is still remains true in Ethiopia context [6].
The donkey (equusasinus) is a domesticated race of African wild ass. The term ass is normally used for animal found in the wild where as the term donkey is used for domesticated animals. The donkey performs hard work under variable agro climate condition and withstands scarcity of feed. hardiness, little maintenance and low purchase price have made the donkey the cheapest and suitable means of transport over the centuries [7]. Generally the mountains and rugged trials of Ethiopia land scrape has treble time consuming and difficult which made equides remain the only means of transportation [8].

The donkey considered a better than other draught animals because of in heritance tolerant for dehydration, low sweat rate and good thermo ability. Donkeys are harder than mules and ponies under short term feed stress. Donkeys have been used to catty arms and ammunition to the different terrains that mechanized vehicles cannot reach easily [7]. Despite all this equids receive less attention in terms of feeding, health and management cares [9].

Equines assume an important place and act as multipurpose animals in the rural and urban society. however, management constraints like

*Corresponding author: Birhanu Abera, Asella Regional Veterinary Laboratory, Asella, Ethiopia, Tel: +251913333944; E-mail: birhanuabera27@ yahoo.com

Received January 22, 2017; Accepted February 27, 2017; Published February 28, 2017

Citation: Assefa G, Abera B, Nur A, Lemma D, Keno L, et al. (2017) The Major Cause of Lameness and Associated Risk Factors in Working Donkey in and around Hawassa Town, Ethiopia. J Vet Sci Technol 8: 427. doi: 10.4172/2157-7579.1000427

Copyright: ( 2017 Assefa G, et al. This is an open-access article distributed under the terms of the Creative Commons Attribution License, which permits unrestricted use, distribution, and reproduction in any medium, provided the original author and source are credited. 
feed shortage, traditional health care, absence of grooming and hoof care, housing problems and different cruelties on the animal together with occurrence of parasite, infectious disease and physical injuries render efficient use of donkeys impossible [10].

Hard working donkeys (pack and cart) were providing 1-3 kg concentrate rations, where as donkeys for light to moderate work were depend on grazing or inadequate fodder, donkeys were deprived of vaccination, deworming and veterinary aid, debility, wounds and abrasion, parasitic infestation, lameness, bite cases, respiratory and digestion disorders were the common ailments affecting $10-40 \%$ of the working donkeys [7].

A variety of disease condition hinders the utilization of donkey, among which lameness contributes a significant impact. Lameness is an indication of structural and functional disorders in one or more limbs that is manifested during progression or in standing position. Lameness cause animal acute pain in the foot, leg or joints, often resulting in lame. A sever case may mean that the animal is unable to bear the pain putting its hoof to the ground. Lameness can include hoof problem for example where they have picked up nail or other sharp objects through the sole after leading to infection, strained muscle or tendons; joint problems and traumatic injuries caused by accident. Lameness can be caused by trauma, congenital or acquire anomalies, infection. Metabolic disturbance, circulatory and nervous disorder or any combination of those.

Lameness is one of the most prevalent health problems in the donkeys. Lameness is not a disease, but a manifestation of either pain caused by any impediment in the musculoskeletal system or, if pain is not involved, of mechanical lameness, although a combination of the two frequently exists. Mechanical lameness is the best typified by fibrotic myopathy with its characteristic in gait abnormality, but can also be the result of restriction. Pain related lameness can be classified as weight bearing (supporting leg) or non-weight bearing (swinging leg) lameness. Although lameness most often is composed of both a supportive leg lameness may originate from anywhere in the limb (proximal or distal) while swinging leg lameness, although often believed to represent a proximal problem or distal [11]. Most important predisposing factors ultimately leading to hoof problems were found to be poor housing, standing in muddy areas for long period, disproportionate harnessing design unskilled furriers and neglect of the car accorded to the hoof [12].

The cause of lameness is multifactorial and its occurrence is associated with risk factors such as nutritional, climatic, housing, breed and age of animals and as squeal of other disease [13]. factors that predispose to lameness include physical immaturity e.g., bones that are anatomically normal but biochemically weak due to the animal at the onset of training or bone that is abnormally weak due to developmental orthopedic disease) and monotonous repetitive stresses on bones [11]. Lameness has got to be treated, otherwise the affected animal will not be able to get about grazing effectively, it may be bullied and it will be lose weight and because lameness is often associated with pain, it is usually on animal welfare problem. There are many possible causes of lameness but for many type, the earlier treatment is given the more likely it is result in permanent cure [14].

Although lameness has been reported as one of the health problem of working donkeys affecting their health and welfare, little attempt has been made to characterize the nature of lameness in working donkey in Ethiopia. Recognizing early assign of lameness is very helpful in reduction of loses due to lameness. Therefore the objective of this study is to identify the types and cause of lameness in working donkeys and to determine associated risk factors of lameness in study area.

\section{Materials and Methods}

\section{Study area}

The study was conducted in and around hawassa town, the capital city of sidama zone, which is located in the northern parts of southern nations, nationalities and people's region (SNNPR), Ethiopia and is located on the shore of rift valley lakes and found at $270 \mathrm{~km}$ south of Addis Ababa with a total land area $6793.6 \mathrm{~km}$ geographically the area lies between 427 ' and 8, 30'N latitude and 34, 21"E longitude [15]. During the study period, Hawassa received an annual average rain fall ranging from 0-3.4 mm and with a mean temperature of the area of $14^{\circ} \mathrm{C}-29.1^{\circ} \mathrm{C}$ with a mean relative humidity of $51.8 \%$ and with an average altitude of $1790 \mathrm{~m}$ above sea level (Meteorology, 2008) the average house hold size is 5-6 years. The total livestock population of Sidama zone is (including Hawassa is estimated to constitute 1,573,378 cattle, 183,462 goat, 221,505 sheep, 49,150 horse, 42,653 asses, 3,959 mule, $1,196,56$ poultry and 73,479 bee hives [3].

\section{Study population and sampling}

The study animals were conducted on working donkeys that are found in and around hawassa town. The study was conducted from November 2007 to May 2008 in Hawassa town. In those months of study; donkeys that are brought to clinic and visits to certain area were examined for lameness. The study protocol or design were done by a questionnaire survey and physical examination techniques were used to study the types, cause and associated risk factors of lameness in working donkeys, purposive sampling technique was used. Donkeys presented to clinic were examined for lameness indicators. A total 205 lame sample size with expected prevalence of $16 \%$ using the formula [16].

$$
n=\frac{1.96^{2} \times P \exp (1-P \exp )}{d^{2}}
$$

Whereas; $\mathrm{n}=$ number of study population

$$
\begin{aligned}
& \text { Pexp=expected prevalence } \\
& \mathrm{d}=\text { desired Precision }
\end{aligned}
$$

\section{Study methodology}

Physical/visual examination: This is done on lame donkeys to generate categorical variables that help to quantify and describe the magnitude of musculoskeletal disorders. Visual examination, examination by manipulation and palpation was done in diagnosis of lameness. Clinical/ physical examination like;

Examination at rest: this examination was done at a distal, then up on close, viewing the animal from front, side and behind to asses symmetry of lameness, conformation, the condition and alteration in posture, weight shifting and pointing. At close observation each limb was observed and compared to its opposite.

Examination at exercise: This is to identify the lameness involved and the degree of lameness and in coordination in movement. Each selected donkey (lame donkey) was examined while it is walking and trotting, and to categorized the degree of lameness on examination and categorized as grade 1 , grade 2 , grade 3 and grade 4 , following observation of the animal from a disease, close examination of the limbs by palpation and manipulation. While the animal is being trotted, to see whether the limb carried in straight line or adducted, abducted or circumducted during progration. Also look for any deviation in long 
Citation: Assefa G, Abera B, Nur A, Lemma D, Keno L, et al. (2017) The Major Cause of Lameness and Associated Risk Factors in Working Donkey in and around Hawassa Town, Ethiopia. J Vet Sci Technol 8: 427. doi: 10.4172/2157-7579.1000427

Page 3 of 5

axis of body during movement. When both limbs are lame they are carried stiffly and the group movements are not reliable for diagnosis of lameness. The head movement seen in lameness of one of the fore limbs may however be seen in case of lameness in opposite hind limb also at animal on one hind limb may be suspected to be lame on opposite forelimb this is called cross lameness. Correct diagnosis in cross lameness is made by observing the group movement also. When one fore limb and the opposite hind limb are lame the condition is called diagonal lameness.

Detail examination of lame limb: this examination is used to locate the exact seat of lameness. The various bones, joint, tendon and sheathe was palpated, flexed, abducted, adducted to know the exact seat of the area for the cause of lameness. Local inflammatory lesions were detected by this examination [17]

Questionnaire survey: This is a structured questionnaire is designed to collect data on information related to lameness like manage mental practices and associated risk factors. This interview was carried out donkey owners and cart drivers.

Data analysis: Data that are collected during study was computed and analyzed with Ms excel and using stat 7 software against all results that are collected from the study animal to determine significant differences among different causes.

\section{Results}

\section{Questionnaire survey}

The result of cross sectional study conducted from December 2007 to May 2008 to determine the causes of lameness in working donkeys and associated risk factor. A total of 205 working donkey owners were examined to investigate the cause of the lameness in working donkey that are found in and around hawassa town. as the involvement of limbs affected, $50.24 \%$ is hind limb and $43.41 \%$ is fore limb and $6.34 \%$ is both limbs affected (Table 1). The pattern of foot inspection when donkey became lame is (96.6\%), no inspection (2.0\%) and immediately after work (1.4\%) (Table 2). The duration of relative lameness $>$ month is $(52.7 \%)$, less than week $(7.3 \%)$ and less than month (40.0\%) (Table 3 ). The house types of working donkey, roofed is (59\%) and open air (41\%) (Table 4). The floor type of the donkey's house sand /soil type is (93.2\%), concrete and stone layer is (3.4\%) (Table 5). The driving speed of working donkey, the average speed is $(74.1 \%)$, fast (17.5\%) and slow (4.4\%) (Table 6). The onset of lameness of working donkey $(98.5 \%)$ is during work and after work (1.5\%) (Table 7$)$. The treatment of lame donkey by rest is $(94.3 \%)$ and brand $(5.7 \%)$ (Table 8$)$.

\begin{tabular}{|c|c|c|}
\hline Involved Limb & Frequency & Percentage \\
\hline Fore limb & 89 & 43.41 \\
\hline Hind limb & 103 & 50.24 \\
\hline Both & 13 & 6.34 \\
\hline Total(n=205) & $\mathbf{2 0 5}$ & $\mathbf{1 0 0}$ \\
\hline
\end{tabular}

Table 1: The lame donkeys in terms of limb affected.

\begin{tabular}{|c|c|c|}
\hline Inspection pattern & Frequency & Percentage \\
\hline No inspection & 4 & 2.0 \\
\hline After work & 3 & 1.4 \\
\hline When lame & 198 & 96.6 \\
\hline Total & $\mathbf{2 0 5}$ & $\mathbf{1 0 0 . 0}$ \\
\hline
\end{tabular}

Table 2: The pattern of inspection of donkey's foot.

\begin{tabular}{|c|c|c|}
\hline Duration of lameness & Frequency & Percentage \\
\hline Less than a week & 15 & 7.3 \\
\hline Less than a month & 82 & 40.0 \\
\hline More than a month & 108 & 52.7 \\
\hline Total & $\mathbf{2 0 5}$ & $\mathbf{1 0 0}$ \\
\hline
\end{tabular}

Table 3: Duration of lameness in working donkeys.

\begin{tabular}{|c|c|c|}
\hline House Type & Frequency & Percentage \\
\hline Open air & 84 & 41 \\
\hline Roofed & 121 & 59 \\
\hline Total & $\mathbf{2 0 5}$ & $\mathbf{1 0 0}$ \\
\hline
\end{tabular}

Table 4: The relative house type of working donkey.

\begin{tabular}{|c|c|c|}
\hline Floor Type & Frequency & Percentage \\
\hline Concrete & 7 & 3.4 \\
\hline Sand/Soil & 191 & 93.2 \\
\hline Stone & 7 & 3.4 \\
\hline Total & $\mathbf{2 0 5}$ & $\mathbf{1 0 0}$ \\
\hline
\end{tabular}

Table 5: The relative floor types of donkey's house.

\begin{tabular}{|c|c|c|}
\hline Driving Speed & Frequency & Percentage \\
\hline Fast & 36 & 17.5 \\
\hline Average & 160 & 78.1 \\
\hline Slow & 9 & 4.4 \\
\hline Total & $\mathbf{2 0 5}$ & $\mathbf{1 0 0 . 0}$ \\
\hline
\end{tabular}

Table 6: The relative speed of working donkey.

\begin{tabular}{|c|c|c|}
\hline Onset of Lameness & Frequency & Percentage \\
\hline During Work & 202 & 98.5 \\
\hline After work & 3 & 1.5 \\
\hline Total & $\mathbf{2 0 5}$ & $\mathbf{1 0 0}$ \\
\hline
\end{tabular}

Table 7: The relative on set of lameness on working donkey.

\begin{tabular}{|c|c|c|}
\hline How alleviate Lameness & Frequency & Percentage \\
\hline Branding & 6 & 5.7 \\
\hline Rest & 199 & 94.3 \\
\hline Total & $\mathbf{2 0 5}$ & $\mathbf{1 0 0 . 0}$ \\
\hline
\end{tabular}

Table 8: The donkey owner for the treatment of lame donkey.

The pattern of foot inspection when donkey became lame is when donkey became lame (96.6\%), immediately after working $(1.4 \%)$ and no inspection $(2.0 \%)$ where recorded (Table 2$)$.

\section{Physical/visual examination}

The type of lameness that was encountered during study period was $47.3 \%$ is supportive leg lameness. With the significant $(p<0.0001)$ (Table 9). As the primary cause of lameness is working donkey $28.3 \%$ is muscle and ligament problem and other associated risk factor(mixed) is $27.0 \%$ with extreme significant of $(p<0.0001)$ (Table 10). As use of working donkey in the study area is cart pulling (96.6\%) and pack working donkey (3.4\%) (Table 11).

\section{Discussion}

The overall prevalence of muscular skeletal disorder; including hoof over growth and inter digital skin hyperplasia that did not cause lameness, for all category of animals was $16.3 \%$ [13].

The result of this study revealed that lameness is of importance to 


\begin{tabular}{|c|c|c|}
\hline Types of lameness & Frequency & Percentage \\
\hline Hanging & 9 & 4.4 \\
\hline Lateral & 5 & 2.4 \\
\hline Supporting & 97 & 47.3 \\
\hline Pointed & 82 & 40.0 \\
\hline Pointed & 12 & 5.9 \\
\hline Total & $\mathbf{2 0 5}$ & $\mathbf{1 0 0}$ \\
\hline
\end{tabular}

$\mathrm{X} 2=194.6, \mathrm{df}=4, \mathrm{P}<0.0001$

Table 9: The relative types of lameness in working donkey.

\begin{tabular}{|c|c|c|}
\hline Primary cause of lameness & Frequency & Percentage \\
\hline Joint Problem & 44 & 21.5 \\
\hline Bone Problem & 11 & 5.4 \\
\hline Tendon Problem & 41 & 20.0 \\
\hline Muscle and ligament & 58 & 28.3 \\
\hline Hoof problem & 27 & 13.2 \\
\hline Mixed & 55 & 27.0 \\
\hline
\end{tabular}

$X 2=38.3, d f=5, P<0.0001$

Table 10: The percentage of major cause of lameness in working donkey.

\begin{tabular}{|c|c|c|}
\hline Use & Frequency & Percent \\
\hline Cart & 198 & 96.6 \\
\hline Pack & 7 & 3.4 \\
\hline Total & $\mathbf{2 0 5}$ & $\mathbf{1 0 0 . 0}$ \\
\hline
\end{tabular}

Table 11: Number of lame donkeys that are examined during study period

the healthy and wellbeing of working donkey. The higher percentage of affected leg is hind limb (50.24\%), fore limb (43.42\%) and in both (6.34\%). The major cause of hind limb lameness is beating donkeys up on working and poor hygienic condition this result is the same with Bolbol and Sahel reported in upper Egypt [18].

The inventory of draught donkey kept by the owner is more of male donkeys (98\%) because the draught power of male donkey is greater than female donkey and also the possible reason could be the economic return associated with their keeping.

During performing the draught work, those animals were subjected to different kinds of cruelties and stress by the owners due to varies reasons. They use beating for the highest speed and poor consideration of owner to the well being of donkey is evident. The reasons for this condition are the poor knowledge of animal health and the focus of owners only on the income.

The frequent occurrence of lameness is during work (98.5\%) because of several cruelties and stresses by the owner during work due to varies causes the first and the major cause of lameness in working donkey is muscles and ligament problems (28.2\%) may be due to short period of rest for donkeys, after rest starting with high speed and the presence of hoof over growth (33.2\%), the highest duration of lameness due to other causes on the working donkey and over working, if duration of lameness is greater than a month $(57.7 \%)$,this may be the main predisposing factor for tendon luxation together with hoof over growth and causing much of weight bearing on the un affected limb leading to atrophy of muscle of the opposite limbs and causes permanent lameness. The second most causes of lameness is joint problem. This may due to over working of the donkey and hoof over growth. The $3^{\text {rd }}$ major cause is tendon problem $(20.0 \%)$ the probable cause of this conditions is because of donkey exposed to over loading. The $4^{\text {th }}$ major cause is hoof problem (13.2\%). The percentage hoof problem in donkey by Addisalem (25.5\%) is twice as recorded by this study (13.2\%) but it is almost similar with (Moti,2005)(15\%) were reported
[10]. The possible reason for recording the low hoof problem is that the establishment of help aid in the town/zone and weekly treatment of donkey by donkey sanctuary in their site and the management aspect of the donkey is good(daily clearance of donkeys house (-\%),59\% of donkey is housed/roofed, high inspection of donkeys hoof immediately the donkey became lame(96.6\%) and the highest working donkey on the soil(93.2\%) rather than concrete $(3.4 \%)$ and atone/asphalt $(3.4 \%)$ $(\mathrm{P}<0.0001)$. The $5^{\text {th }}$ rank is bone problems $(5.4 \%)$ this is to indicate that fracture and related orthopedic problems. This low result is may be due to the donkeys' owners' care for breakage of donkey's legs by considering the economic impact for treatment of broken donkey.

As per type of lameness in working donkey on study is supportive leg lameness (47.0\%), the possible cause of this is, the donkeys" owners work by lame donkey until it become unable to walk because of the owner purchase donkey with high cost and the donkey owners haven't any other possible income besides the knowledge of donkey owners on lameness identification earlier is low. The $2^{\text {nd }}$ most common types of lameness is hinder leg lameness (40.0\%) due to donkey suffering from lameness exhibit the clinical signs only during rest; which is show by pointing of leg while standing.

Lameness is one of the major factors for working equine leading to low power or energy generation and loss of animal and having high economic impact, this is true in all animals including dairy animals. Thus further studies must be conducted on lameness to overcome loss animal power and economy.

\section{Conclusions and Recommendations}

The result of the present study conducted on working donkeys for six months from November 2007 to May 2008 in and around Hawassa town showed that lameness of donkeys is one of the major conditions in study area affecting the well being of the animals. The major cause of lameness is working donkey in study area is muscle and ligament $(28.3 \%)$ and joint problem $(21.5 \%)$ and other associated mixed factors $(27.0 \%)$ are encountered during the study period. The most common types of lameness were supportive leg lameness (47.3). This shows that lameness in the area becoming high prevalent, if no veterinary aid and attention of any help to alleviate these problems. Those lameness conditions have an impact on the power working of the animal. Therefore, based on the above conclusions the following recommendations are forwarded:

* Donkeys as drought animal will play a pivot role for many decades to come, therefore, it is necessary that a comprehensive research program for their ration and efficient use in future to be formulated.

* Short courses on drought donkey management, disease control, health cover, handling, training, welfare, housing, feeding and first aid should be launched in rural and urban area for drought animal power owners.

* There is dire need to conduct research on animal derived vehicles, implements and other equipment to make the more appropriate for animal from welfare point as well as the efficiency.

* There should be regular inspection of hoof, daily cleaning of house of donkey and trimming of the overgrown hoofs.

* The donkey sanctuary aid should be expanded throughout the country to achieve the wellbeing and health of working donkeys. 
Citation: Assefa G, Abera B, Nur A, Lemma D, Keno L, et al. (2017) The Major Cause of Lameness and Associated Risk Factors in Working Donkey in and around Hawassa Town, Ethiopia. J Vet Sci Technol 8: 427. doi: 10.4172/2157-7579.1000427

\section{References}

1. Wilson RL (1991) Equine in Ethiopia. In: Fieldings D, Pearson RA (eds.) Donkeys, mules and horses in tropical agricultural development. Preceding of colloquium help 3-6 september 1990, Edinbrough, Scotland, Center for tropical veterinary medicine, University of Edenborough, UK, pp: 33-47.

2. Blench R, Champman R, Slay Marker T (2003) A study of role of livestock inpoverty reduction strategy papers. pro-poor livestock initiative working paper, FAO, pp: 52

3. CSA (2004) Ethiopia- Agricultural Sample Enumeration, Farm Practice 20012002 (1994 E.C) Authority, Federal Democratical of Ethiopia.

4. Pritchard JC, Lindberg AC, Main DCJ, Whay HR (2005) Assessment of the welfare of working horses, mules and donkeys using health and behavior parameters. Prev Vet Med. 12: 265-283.

5. Biffa D, Woldemeskel M (2006) Causes and Factors Associated With Occurrence of External Injuries in Working Equines in Ethiopia. International J Appl Res Vet Med. 4: 1-7.

6. Feseha GA,Yilma JM, Sevandense ED, Mohammed A (1991) Health problem of working donkey in Debre zeit and Menagesha region of Ethiopia in FAO.

7. Singh MK, Gupta AK, Yadav MP (2005) The donkey; its role and the scope for better management, Livestock International. 9: 18-20.

8. Hassen K (2000) A preliminary study on the socio economic importance, health problem and other management constraints of horses in mid and high land area of north Gonder, DVM thesis, FVM, AAU, Debre zeit, Ethiopia.

9. Gizaw (1987) Policy and strategy option to ward rapid development of Ethiopia livestock improvement conference, IAR, Ethiopia.
10. Addisalem H (2005) Assessment of health and welfare problems of donkeys and mules in SNNP region. DVM thesis, Faculty of veterinary Medicine, AAU pp: 452-453.

11. Khan CM, Scott line (2005) The merck veterinary manual, 9th edn. Merck and Co., Inc., white house station, NJ, USA, pp: 618-619.

12. Moti $Y$ (2005) Assessment of hoof associated problem in cart horses in five town of SPANA- Ethiopia operation sites. Centeral Ethiopia, DVM thesis. FVM. AAU. Debre zeit. Ethiopia, pp: 480.

13. Alemayehu L, Fikre Legabo, Azage Tegegn (1999) Lameness as a disease of intensification in dairy cattle under urban and peri urban production system in Addis Ababa milk shed. Bulletin of Animal Health and Production in Africa. 49: 254-261.

14. Marjories O (1993) Lameness is caused by many factors which differ between individual cows and farms. Reducing the number of lame cows on your farm therefore requires a long-term, planned approach that is supported by the whole farm team.

15. Ghirottic M (1995) Farming practices and pattern in coffe growing mid land Sidama-Ethiopia,Msc thesis, Haramaya University, pp: 1-11.

16. Thrusfield M (2007) Veterinary Epidemiology. 3rd edn, Blackwell Science Ltd, Oxford, pp: 244-245.

17. Kelly WR (1974)Veterinary clinical Diagnosis. 2nd edn., Pub Baillier Tindale London, UK, pp: 335-346.

18. Bolbol AE, Saleh AS (1987) Survey on equine hoof affection in Upper Egypt (Abstract). Jounal of the egypt veterinary medicine association. 47: 545-553. 